\title{
Development of New Instrument for Evaluating Leg Motions Using Acceleration Sensors
}

\author{
Takaki ITOH ${ }^{1}$, Yukie KUMAGAI², Ikuharu MORIOKA³ ${ }^{3}$ Shinji MAE , \\ Toshihiro NAKA ${ }^{5}$, Hiroyasu UENISHI ${ }^{2}$ and Toshiko MATSUOKA ${ }^{2}$ \\ ${ }^{1}$ Industrial Technology Center of Wakayama Prefecture, Wakayama, Japan \\ ${ }^{2}$ Wakayama Medical University, Wakayama, Japan \\ ${ }^{3}$ Wakayama Medical University, School of Health and Nursing Science, Wakayama, Japan \\ ${ }^{4}$ Nature Core Science Inc., Kainan, Japan \\ ${ }^{5}$ Wakayama University, Faculty of Education, Wakayama, Japan
}

\begin{abstract}
The purpose of this study is to develop a new system for measuring leg motions using a portable three-dimensional accelerometer. The measuring system is composed of acceleration sensors (MicroStone, MA3-10Ac), a data logger, a data reader, and a personal computer. The personal computer draws a graph of the acceleration of movements (i.e., accelerogram) from the output signals of the acceleration sensors. We then calculated the average acceleration to evaluate leg motions. We drew the accelerograms from 19 young subjects and 36 elderly subjects during the performance of physical fitness activities and walking. Different accelerograms were obtained from two subjects for different walking styles. The average accelerations at the lumbar, ankle and toe points were higher at all axes during movements from the physical fitness activities in the elderly subjects. The accelerations of leg motion at the knee point were, however, lower in the up and down axis in the elderly subjects than in the young subjects, although they were higher in the back and forth and the right and left axes. The new instrument has enabled us to evaluate leg motions by measuring three-dimensional acceleration during the performance of physical fitness activities and walking. The average accelerations of leg motions showed age-related changes. Thus, the average acceleration of leg motions may be used as a new index for evaluating leg motions at the dynamic state.
\end{abstract}

Key words: leg motion, three-dimensional accelerometer, accelerogram, dynamic state, age-related changes

\section{Introduction}

In the last few years, several investigations have been devoted to the study of preventing a fall among elderly persons over 65 . The investigations show that about $20 \%$ of elderly persons had experienced a fall (1-4). The cause of a fall in elderly persons seems to be a decrease in the quadriceps power and in coordination of movements (5-11). Much effort has been made on measuring the muscle power of the legs and movement coordination, and this effort is beneficial to find ways to prevent a fall (12-14). A leg myodynamiometer has been used to measure the muscle power of the legs (12-14). This device,

Received Aug. 31, 2006/Accepted Feb. 22, 2007

Reprint requests to: Takaki ITOH

Industrial Technology Center of Wakayama Prefecture, Wakayama, Japan

TEL: +81(73)477-1271, FAX: +81(73)477-2880

E-mail: t-itoh@wakayama-kg.go.jp however, increases stress among subjects, particularly elderly persons whose muscle power of their legs is low (12-14). Electromyography is used to electrically measure the construction of leg muscles; however, it is impossible to measure muscle power itself (15). A gravicorder is used for measuring movement coordination at the static state in a clinical setting. It is, however, impossible to measure movement coordination in the dynamic state (16-19). It has been difficult to evaluate the muscle power of the legs and movement coordination correctly at the same time (15-21).

Recently, a portable three-dimensional accelerometer has been developed (20). This device can measure movement coordination; however, it is impossible to measure leg motions and muscle power using this device (20). It is also difficult to measure instantaneous movement because the measuring time interval is long (20).

The purpose of this study is to develop a new system for measuring leg motions using a portable three-dimensional 
accelerometer. In this study quantifying leg motions using acceleration sensors was carried out. We also clarified the relationship between leg motions and the signals from the acceleration sensors.

\section{Methods}

\section{Measuring system}

The schematic of the new measuring system is shown in Fig. 1. The measuring system is composed of acceleration sensors (MicroStone, MA3-10Ac), a data logger, a data reader, and a personal computer. The frequency characteristic range of the acceleration sensors is $0.8-1000 \mathrm{~Hz}$ and their sensitivity is $20 \mathrm{mV} / \mathrm{m} / \mathrm{s}^{2}$. A subject wears a data logger and the acceleration sensors while performing physical fitness activities and walking. The data logger can accumulate twelve output signals from four sensors for about 20 minutes with a $10 \mathrm{~ms}$ time interval. The EEPROM, a data box in the data logger, is taken from the data logger after the measurement. The accumulated data in the EEPROM is transferred through a data reader to a personal computer by RS232C.

At the static state, the output of the sensor was $2.5 \mathrm{~V}(0$ $\left.\mathrm{m} / \mathrm{s}^{2}\right)$. The output varied from $0\left(-100 \mathrm{~m} / \mathrm{s}^{2}\right)$ to $5 \mathrm{~V}\left(100 \mathrm{~m} / \mathrm{s}^{2}\right)$ with the acceleration of movements. The output voltage of an acceleration sensor is converted into a digital value by an 8-bit analog-digital converter. As a result, the static state corresponds to 128 . An acceleration range $\pm 100 \mathrm{~m} / \mathrm{s}^{2}$ corresponds to a digital value from 0 to 255 .

The sensors attached to a subject are shown in Fig. 2. Four sensors were placed on the body surface of the vertebral column on the Jacoby line that connects the right and left tops of the ilium (lumbar point), the lateral aspect of the right thigh of about $2 \mathrm{~cm}$ from the upper part of the lateral epicondyle of the right femur (knee point), the point about $2 \mathrm{~cm}$ from the upper part of the right lateral malleolus (ankle point), and the upper side of the ossa cuneiformia to the right foot (toe point). The body surface of the eminence of the bone is suitable for setting the sensors because of the mounting stability; however, mounting the sensors on this area prevents flexion. Consequently, we displaced the mounting point by about $2 \mathrm{~cm}$. A rubber band was used to fix the sensors to the body surface.

The arrows show the measuring directions of the threedimensional acceleration sensors (Fig. 2). The measuring directions of the sensors were defined at the static state before the subjects performed physical fitness activities and walking. Three directions of the sensors, namely, X, Y and Z, corresponded to the axis parallel to the sagittal axis (Back-Forth; B-F), horizontal axis (Right-Left; R-L) and vertical axis (UpDown; U-D) of a standing subject. These directions, however, changed depending on the position of the body during movements, because the measuring directions of the sensors were originally fixed at mutually vertical positions. A light emitting diode was prepared to easily observe the movements of a subject.

\section{Accelerogram of measuring system}

The personal computer draws a graph of the direction of the acceleration of movements depending on time, such as a

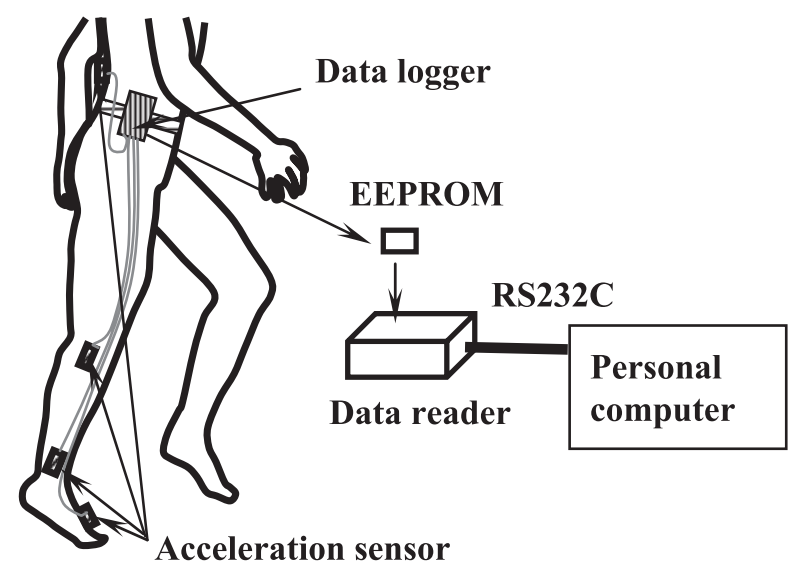

Fig. 1 Schematic of measuring system for leg motions.

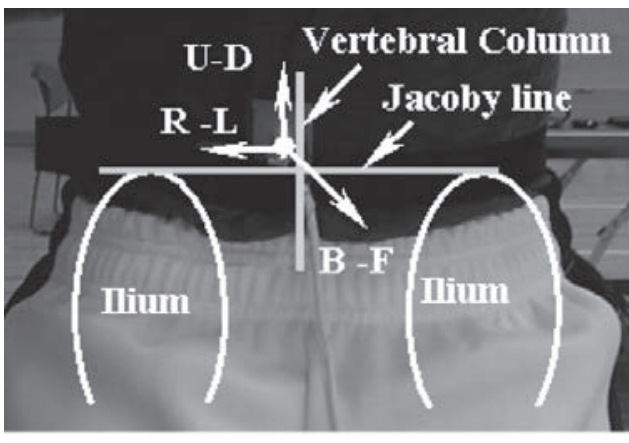

(a) Back view

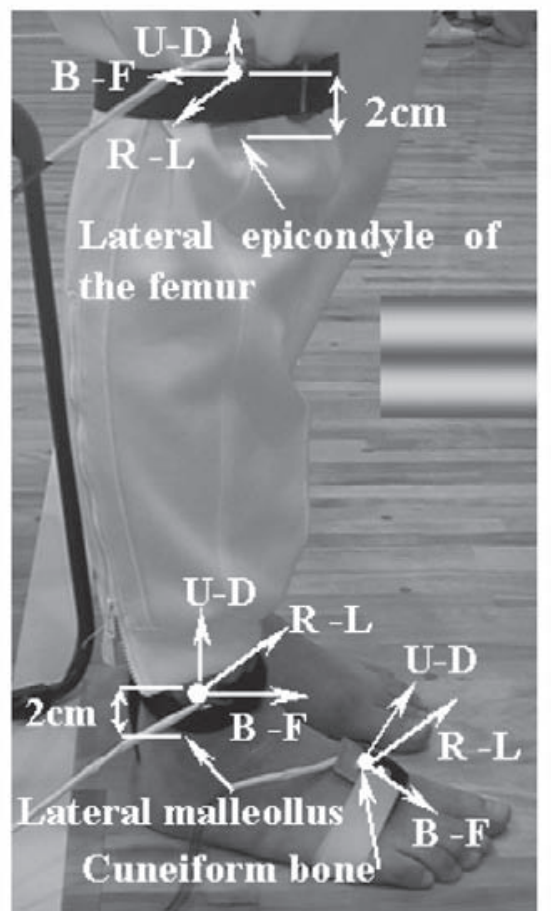

(b) Side view

Fig. 2 Image of sensors attached to subject (B-F: back and forth, R-L: right and left, U-D: up and down). (a) Back view and (b) side view. 
vertical direction, or a horizontal direction. This graph is called an accelerogram. Figure 3 shows the accelerogram during the kick up motion of subject A aged 20. It took one minute to attach the measuring system to the subject. She sat on a chair with her lower legs dangling and she raised her right lower leg

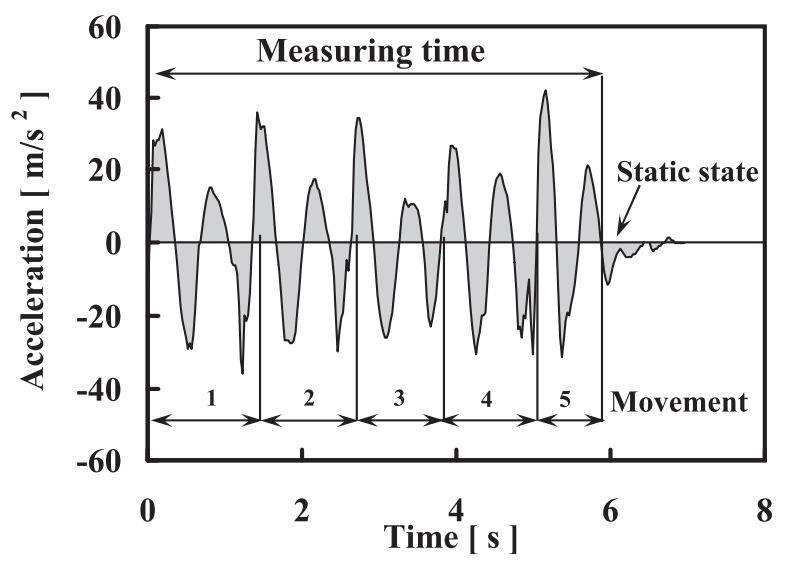

Fig. 3 Accelerogram in kick up movements of subject A.

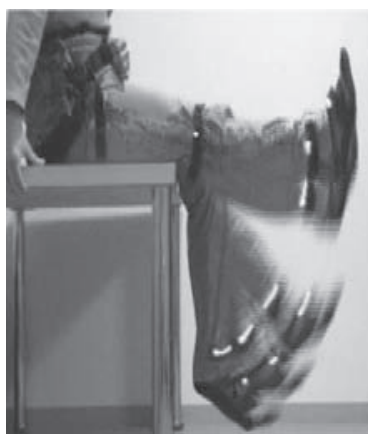

(a) Kick up

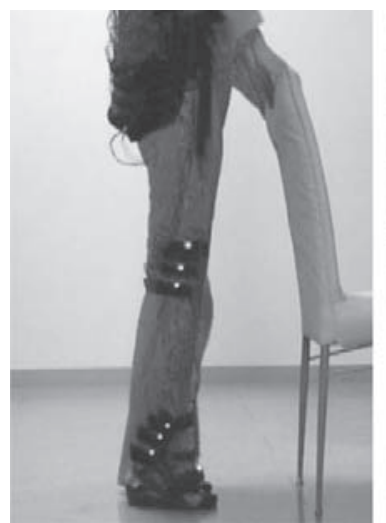

(e) Heel up

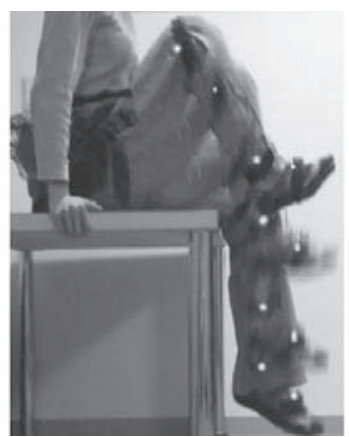

(b) Knee up

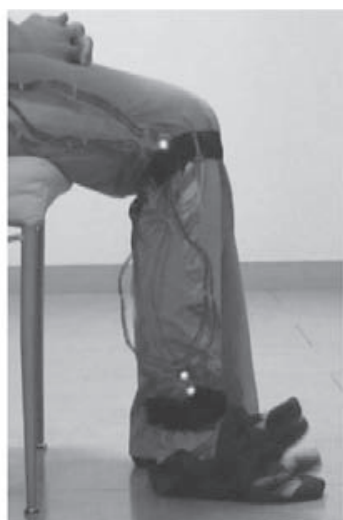

(f) Toe up with her knees settled, similarly to a position for kicking a ball. The measuring time is between half a minute and 1 minute. The accelerogram shows the amplitude and direction of the acceleration of the leg motions. We then calculated the acceleration of the leg motions to evaluate their movement. After calculating the area indicated by the gray-painted square in Fig. 3 using the trapezoidal rule, the area was divided by the measuring time. The result was called average acceleration $\left(\mathrm{m} / \mathrm{s}^{2}\right)$. This average acceleration directly shows neither the muscle power of the legs nor the movement coordination, because the accelerogram only shows instantaneous leg motions by movements.

Table 1 Number of subjects by age

\begin{tabular}{ccc}
\hline Age [years] & Male & Female \\
\hline $19 \sim 23$ & 10 & 9 \\
$63 \sim 64$ & 0 & 1 \\
$65 \sim 74$ & 3 & 11 \\
$75 \sim 84$ & 9 & 9 \\
$85 \sim$ & 0 & 3 \\
\hline Total & 22 & 33 \\
\hline
\end{tabular}

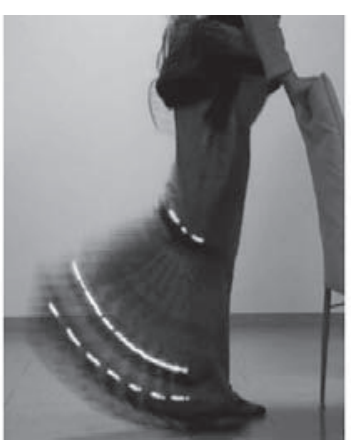

(c) Backward

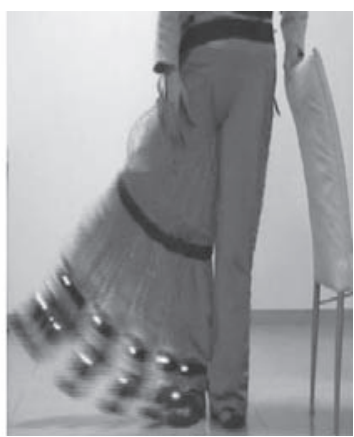

(d) Sideward

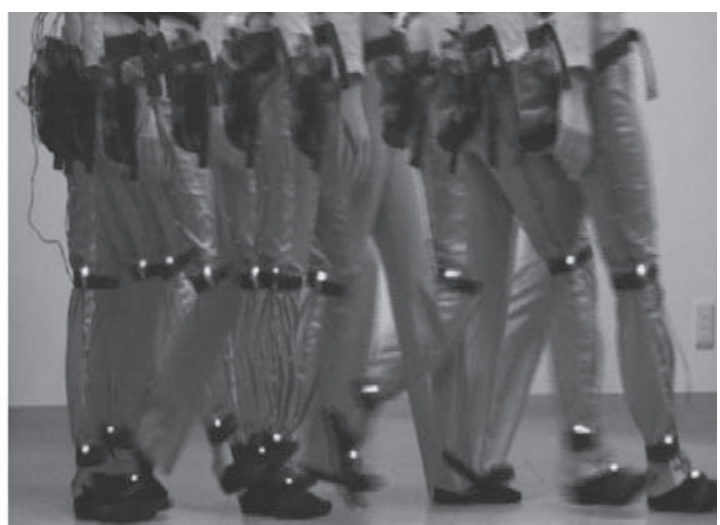

(g) Walking

Fig. 4 Physical fitness activities and walking. (a) Kick up: A subject sits on a chair without a backrest with his/her lower legs dangling (his/her soles are not on the floor) and extends his/her knee joint quickly from a flexed position. (b) Knee up: A subject sits on a chair without a backrest with his/her lower legs dangling (his/her soles are not on the floor), and flexes his/her hip joint quickly while keeping his/her knee joint flexed. (c) Backward: A subject stands holding the backrest of a chair with both hands, and extends his/her right hip joint quickly while keeping his/her trunk settled. (d) Sideward: A subject stands holding the backrest of a chair with both hands, and abducts his/her right hip joint quickly while keeping his/her trunk settled. (e) Heel up: A subject stands holding the backrest of a chair with both hands, and moves both his/her heels up and down while keeping his/her trunk settled. (f) Toe up: A subject sits on a chair without a backrest with his/her soles on the floor, and moves all his/her toes up and down while keeping his/her lower legs settled. (g) Walking: A subject walks a distance of 10 meters. 


\section{Estimation of leg motions}

The young subjects were composed of 10 males and 9 females who were about 20 years old (young group), and the aged subjects were composed of 12 males and 24 females who were over 60 years old (aged group), as shown in Table 1. The subjects had neither leg diseases nor troubles in the usual daily life.

An accelerogram was drawn upon the performance of each physical fitness activity: (a) kick up, (b) knee up, (c) backward motion, (d) sideward motion, (e) heel up, (f) toe up, and (g) walking (Fig. 4). The subjects repeated these movements five times except walking. The different parts of their body were not fixed by bands to be able to measure the average acceleration of their legs during natural movements. The subjects were instructed not to move the different parts of their body as much as possible. The exerted strength for each movement was the best effort exerted by each subject.

Public health nurses in a health center explained the outline of this study to the subjects beforehand. The researcher in charge explained the aims and methods of the study, the protection of individual information, and the possibility of canceling participation with an oral explanation and by providing documents on the study day. Those who agreed to participate were asked to give written informed consent. This study was approved by the Ethical Committee of Wakayama Medical University.

The Student's t-test was used to evaluate the differences in the means between the young and aged groups and between sexes. In all analyses, the level of statistical significance was set at 0.05 . Statistical analysis was carried out using SPPS 11.0J for Windows (SPSS Japan Inc.).

\section{Results}

\section{Accelerogram corresponding to walking styles}

We measured the acceleration of leg movements from a total of 55 subjects. The mean measuring time was about five minutes for both physical fitness activities and walking. All the subjects felt neither pain nor burden from answering the questionnaire after the measurements.

At first, we examined the effects of different walking styles on the accelerogram through all walking cycles. Different accelerograms were obtained from two subjects for different walking styles (Fig. 5). Subject B (aged 75) showed a characteristic walking movement by raising the toe. Subject $\mathrm{C}$ (aged 77) was flatfooted. The amplitude of the accelerogram at the R-L axis was larger in Subject $C$ than in Subject B at both positions.

\section{Average accelerations in young and aged groups}

We calculated the mean and standard deviation of the average acceleration at all points during the physical fitness movements. The results are shown in Table 2.

In males (upper lines in Table 2), the average accelerations at the lumbar point were higher at all axes during the movements in the aged group. Those at the knee point were lower at the U-D axis in the aged group, although the average accelerations were higher at the B-F axis. Those at the ankle point showed a slight difference between the groups. Those at the toe point were higher at the R-L and U-D axes.

In females (lower lines in Table 2), the average accelerations at the lumbar, ankle and toe points were higher at all axes during the movements in the aged group. Those at the knee

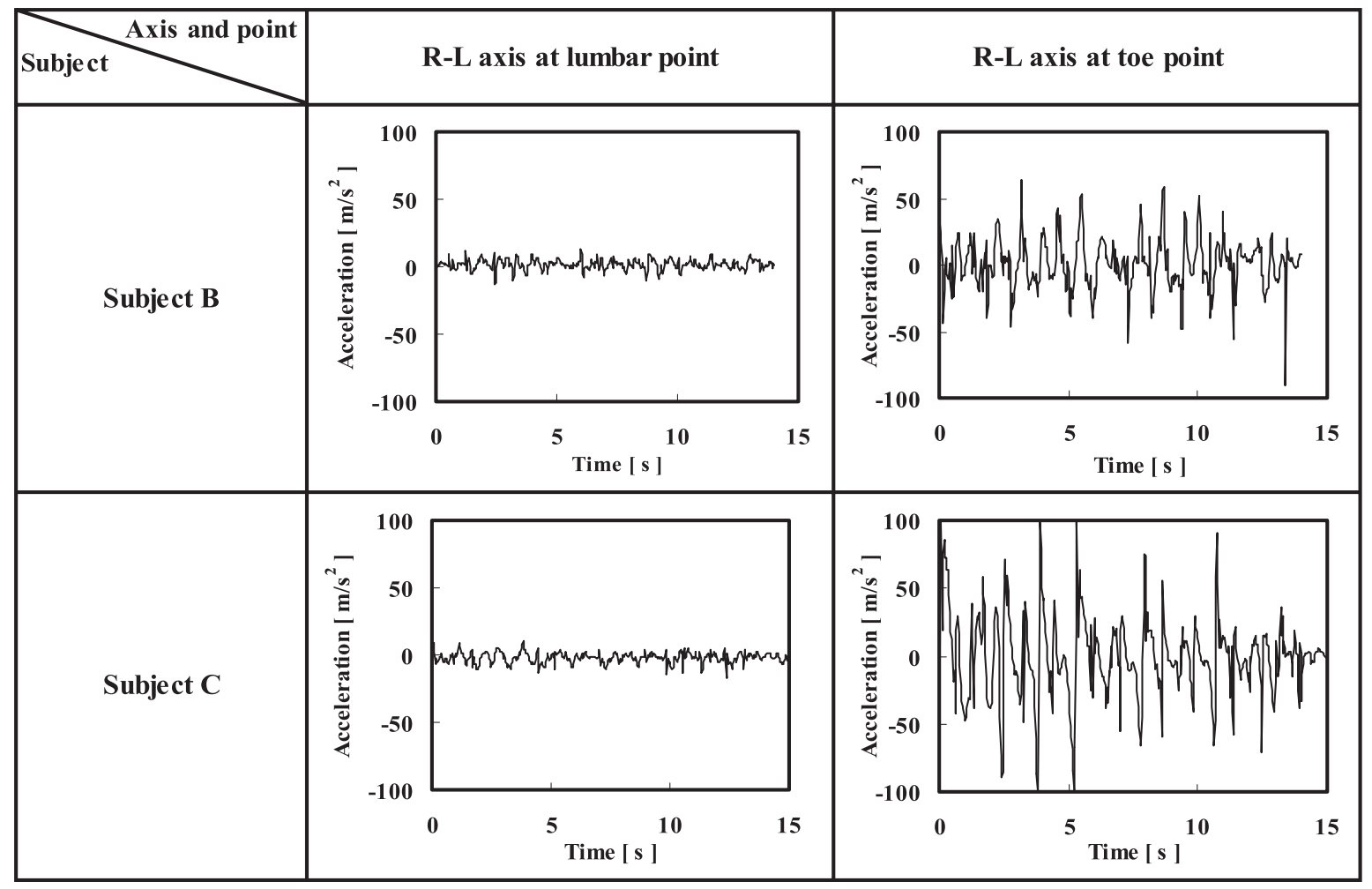

Fig. 5 Accelerograms of subjects B and C at two points during walking (Subject B: $0.71 \mathrm{~m} / \mathrm{s} ;$ Subject C: $0.68 \mathrm{~m} / \mathrm{s}$ ). 
Table 2 Means and standard deviations of average accelerations at all points during physical fitness activities with males (upper lines, young: $n=10$, aged: $n=12$ ) and females (lower lines, young: $n=9$, and aged: $n=24$ )

\begin{tabular}{|c|c|c|c|c|c|c|c|}
\hline & & \multicolumn{2}{|c|}{$\mathrm{B}-\mathrm{F}$ axis } & \multicolumn{2}{|c|}{$\mathrm{R}-\mathrm{L}$ axis } & \multicolumn{2}{|c|}{ U-D axis } \\
\hline & & Young & Aged & Young & Aged & Young & Aged \\
\hline \multirow{12}{*}{$\begin{array}{l}\text { Lumbar: } \\
\text { bone of vertebral } \\
\text { column on } \\
\text { Jacoby line }\end{array}$} & Kick up & $1.2 \pm 0.3$ & $5.5 \pm 4.4 *$ & $0.7 \pm 0.3 \#$ & $6.7 \pm 1.5^{* *}$ & $0.9 \pm 0.4$ & $4.4 \pm 2.0 * *$ \\
\hline & & $1.7 \pm 1.0$ & $10.0 \pm 13.5^{*}$ & $0.4 \pm 0.2$ & $7.9 \pm 10.7 * *$ & $0.6 \pm 0.4$ & $8.2 \pm 10.9 * *$ \\
\hline & Knee up & $2.2 \pm 0.7$ & $4.4 \pm 2.5^{*}$ & $0.9 \pm 0.2$ & $5.6 \pm 1.8 * *$ & $1.3 \pm 0.6$ & $3.5 \pm 1.2 * *$ \\
\hline & & $2.6 \pm 0.9$ & $8.7 \pm 13.3^{*}$ & $0.8 \pm 0.5$ & $6.7 \pm 11.2 *$ & $0.8 \pm 0.5$ & $6.8 \pm 11.3^{*}$ \\
\hline & Backward & $2.7 \pm 0.5$ & $4.7 \pm 2.0 *$ & $1.2 \pm 0.3$ & $6.1 \pm 2.6^{* *}$ & $1.4 \pm 0.4$ & $3.7 \pm 1.1 * *$ \\
\hline & & $3.6 \pm 3.8$ & $5.5 \pm 2.0$ & $1.3 \pm 1.3$ & $6.0 \pm 5.9 * *$ & $2.2 \pm 3.3$ & $4.9 \pm 4.4$ \\
\hline & Sideward & $1.5 \pm 0.3$ & $3.9 \pm 2.4 * *$ & $1.0 \pm 0.4$ & $6.2 \pm 2.3 * *$ & $3.2 \pm 1.0$ & $3.6 \pm 1.1$ \\
\hline & & $1.8 \pm 1.1$ & $5.0 \pm 2.4^{* *}$ & $0.7 \pm 0.4$ & $5.2 \pm 2.2 * *$ & $2.3 \pm 1.9$ & $4.4 \pm 1.4^{* *}$ \\
\hline & Heel up & $2.1 \pm 0.8$ & $10.1 \pm 22.1$ & $2.4 \pm 0.9$ & $10.5 \pm 18.5$ & $0.4 \pm 0.2$ & $10.6 \pm 19.2$ \\
\hline & & $2.1 \pm 0.5$ & $4.2 \pm 4.2 * *$ & $1.5 \pm 0.7$ & $4.9 \pm 2.8^{* *}$ & $0.5 \pm 0.4$ & $4.2 \pm 3.7^{* *}$ \\
\hline & Toe up & $3.1 \pm 3.2$ & $10.9 \pm 11.0^{*}$ & $2.5 \pm 3.0$ & $21.0 \pm 20.3^{*}$ & $1.0 \pm 1.4$ & $21.3 \pm 25.7^{*}$ \\
\hline & & $1.5 \pm 1.6$ & $5.5 \pm 5.7 * *$ & $0.8 \pm 1.3$ & $7.8 \pm 9.8^{* *}$ & $2.8 \pm 6.6$ & $4.9 \pm 6.0$ \\
\hline \multirow{12}{*}{$\begin{array}{l}\text { Knee: } \\
\text { about } 2 \mathrm{~cm} \text { from } \\
\text { upper part of } \\
\text { lateral epicondye } \\
\text { of right femur }\end{array}$} & Kick up & $9.0 \pm 2.7$ & $16.1 \pm 7.9 *$ & $4.0 \pm 1.3$ & $6.2 \pm 2.3^{*}$ & $8.7 \pm 0.2$ & $4.4 \pm 5.1 *$ \\
\hline & & $8.8 \pm 3.1$ & $18.1 \pm 12.1^{* *}$ & $3.7 \pm 1.2$ & $9.8 \pm 13.1^{*}$ & $8.8 \pm 0.1$ & $8.2 \pm 6.7$ \\
\hline & Knee up & $8.0 \pm 2.2$ & $15.5 \pm 6.9 * *$ & $4.5 \pm 1.3$ & $5.6 \pm 1.5$ & $10.0 \pm 0.6$ & $4.0 \pm 3.6^{* *}$ \\
\hline & & $8.8 \pm 4.5$ & $14.7 \pm 10.4^{*}$ & $3.7 \pm 1.2$ & $7.6 \pm 13.2$ & $9.6 \pm 1.0$ & $5.1 \pm 3.3^{* *}$ \\
\hline & Backward & $8.2 \pm 1.7$ & $12.7 \pm 5.6^{*}$ & $4.9 \pm 1.0$ & $4.9 \pm 1.3$ & $8.6 \pm 0.2$ & $3.5 \pm 2.3 * *$ \\
\hline & & $8.1 \pm 5.2$ & $9.3 \pm 5.0$ & $5.6 \pm 4.7$ & $4.2 \pm 1.3$ & $9.2 \pm 1.8$ & $3.8 \pm 1.9 * *$ \\
\hline & Sideward & $10.7 \pm 3.6$ & $11.4 \pm 4.7$ & $7.5 \pm 2.0$ & $7.1 \pm 2.6$ & $8.6 \pm 0.2$ & $4.1 \pm 3.0 * *$ \\
\hline & & $7.9 \pm 4.5$ & $9.0 \pm 4.3$ & $5.5 \pm 3.0$ & $6.1 \pm 1.8$ & $8.7 \pm 0.3$ & $5.1 \pm 3.3^{* *}$ \\
\hline & Heel up & $4.4 \pm 1.8$ & $11.2 \pm 18.4$ & $1.9 \pm 0.7$ & $9.7 \pm 21.9$ & $8.7 \pm 0.2$ & $4.3 \pm 4.9 *$ \\
\hline & & $4.7 \pm 1.4$ & $6.3 \pm 4.1^{*}$ & $2.3 \pm 1.0$ & $3.9 \pm 3.1^{*}$ & $8.7 \pm 0.1$ & $5.4 \pm 3.6^{* *}$ \\
\hline & Toe up & $2.1 \pm 1.1$ & $6.9 \pm 7.8$ & $1.1 \pm 0.4$ & $6.2 \pm 11$ & $9.7 \pm 1.5$ & $3.0 \pm 1.9 * *$ \\
\hline & & $3.5 \pm 4.6$ & $7.2 \pm 8.2$ & $1.8 \pm 1.2$ & $4.0 \pm 5.2^{*}$ & $8.8 \pm 0.3$ & $5.6 \pm 4.5^{* *}$ \\
\hline \multirow{12}{*}{$\begin{array}{l}\text { Ankle: } \\
\text { about } 2 \mathrm{~cm} \text { from } \\
\text { upper part of } \\
\text { right malleolus }\end{array}$} & Kick up & $27.1 \pm 19.4 \#$ & $21.0 \pm 4.5$ & $23.6 \pm 22.8 \#$ & $14.2 \pm 3.9$ & $19.6 \pm 6.3$ & $19.6 \pm 8.9$ \\
\hline & & $10.0 \pm 3.4$ & $19.5 \pm 12.6^{* *}$ & $5.8 \pm 2.3$ & $11.3 \pm 4.3^{* *}$ & $15.7 \pm 3.6$ & $17.9 \pm 5.2$ \\
\hline & Knee up & $25.2 \pm 22.3$ & $16.8 \pm 4.7$ & $22.8 \pm 26.7$ & $12.1 \pm 3.5$ & $12.7 \pm 3.7 \#$ & $16.0 \pm 5.2$ \\
\hline & & $10.2 \pm 5.1$ & $16.5 \pm 8.8$ & $4.3 \pm 3.0$ & $10.8 \pm 6.6^{* *}$ & $8.0 \pm 4.4$ & $14.4 \pm 6.5^{*}$ \\
\hline & Backward & $33.5 \pm 19.4 \#$ & $25.6 \pm 9.9$ & $31.7 \pm 23.1 \#$ & $13.3 \pm 4.3 * \#$ & $15.9 \pm 3.9 \#$ & $16.3 \pm 5.4$ \\
\hline & & $15.3 \pm 8.3$ & $21.2 \pm 8.7$ & $9.3 \pm 6.4$ & $9.7 \pm 3.3$ & $10.3 \pm 5.1$ & $14.8 \pm 11.5$ \\
\hline & Sideward & $26.6 \pm 18.1 \#$ & $23.4 \pm 11.6$ & $27.4 \pm 20.6 \#$ & $16.0 \pm 8.2$ & $18.6 \pm 5.1$ & $14.6 \pm 4.3$ \\
\hline & & $10.3 \pm 5.2$ & $21.9 \pm 9.5^{* *}$ & $10.6 \pm 5.2$ & $13.9 \pm 5.6$ & $13.9 \pm 7.3$ & $13.5 \pm 3.6$ \\
\hline & Heel up & $12.2 \pm 10.7$ & $18.8 \pm 6.9$ & $9.5 \pm 12.2$ & $6.5 \pm 2.3$ & $4.1 \pm 1.8$ & $8.9 \pm 2.8 * *$ \\
\hline & & $6.2 \pm 1.8$ & $19.4 \pm 8.9 * *$ & $2.6 \pm 1.0$ & $8.9 \pm 8.4^{* *}$ & $4.3 \pm 1.4$ & $9.2 \pm 4.6^{* *}$ \\
\hline & Toe up & $16.5 \pm 16.5$ & $16.9 \pm 10.3$ & $13.3 \pm 18.4$ & $7.5 \pm 3.5$ & $4.8 \pm 3.8$ & $10.5 \pm 2.8^{* * \#}$ \\
\hline & & $7.4 \pm 7.8$ & $24.4 \pm 13.6^{* *}$ & $2.8 \pm 3.2$ & $12.1 \pm 12.6^{* *}$ & $5.0 \pm 6.0$ & $12.0 \pm 7.2 * *$ \\
\hline \multirow{12}{*}{$\begin{array}{l}\text { Toe: } \\
\text { ossa cunei- } \\
\text { formia to right } \\
\text { foot }\end{array}$} & Kick up & $18.3 \pm 14.1$ & $24.4 \pm 13.7$ & $15.3 \pm 3.7$ & $20.0 \pm 9.3$ & $19.4 \pm 5.5$ & $25.9 \pm 8.4$ \\
\hline & & $8.3 \pm 3.1$ & $19.1 \pm 7.8^{* *}$ & $12.2 \pm 4.9$ & $15.0 \pm 6.1$ & $14.6 \pm 4.5$ & $23.3 \pm 7.4^{* *}$ \\
\hline & Knee up & $17.3 \pm 18.6$ & $13.6 \pm 7.3$ & $8.1 \pm 1.2$ & $12.6 \pm 6.9$ & $10.1 \pm 2.6 \#$ & $15.4 \pm 6.3^{*}$ \\
\hline & & $4.9 \pm 2.2$ & $13.0 \pm 4.8^{* *}$ & $7.5 \pm 3.1$ & $11.1 \pm 6.7$ & $6.9 \pm 3.5$ & $14.4 \pm 8.3^{* *}$ \\
\hline & Backward & $26.7 \pm 18.0 \#$ & $24.5 \pm 7.2$ & $23.2 \pm 8.0$ & $20.5 \pm 6.4 \#$ & $19.3 \pm 4.7 \#$ & $17.4 \pm 6.9 \#$ \\
\hline & & $9.5 \pm 3.6$ & $20.6 \pm 8.0^{* *}$ & $16.3 \pm 5.8$ & $15.0 \pm 5.9$ & $13.1 \pm 6.5$ & $11.6 \pm 4.8$ \\
\hline & Sideward & $25.1 \pm 13.9 \#$ & $15.6 \pm 6.5$ & $14.1 \pm 3.7 \# \#$ & $19.9 \pm 4.8 *$ & $16.3 \pm 4.6$ & $24.9 \pm 8.1$ *\#\# \\
\hline & & $11.5 \pm 4.3$ & $15.9 \pm 5.9$ & $8.6 \pm 2.4$ & $17.6 \pm 5.0^{* *}$ & $12.0 \pm 6.3$ & $17.1 \pm 6.0^{*}$ \\
\hline & Heel up & $11.1 \pm 7.4 \#$ & $15.6 \pm 6.6$ & $9.7 \pm 5.0$ & $26.7 \pm 10.6^{* * \#}$ & $5.2 \pm 3.1$ & $10.0 \pm 5.3 *$ \\
\hline & & $5.0 \pm 2.2$ & $12.7 \pm 5.8^{* *}$ & $7.1 \pm 3.0$ & $16.5 \pm 7.6^{* *}$ & $4.8 \pm 1.7$ & $7.2 \pm 2.7 * *$ \\
\hline & Toe up & $11.2 \pm 15.3$ & $12.0 \pm 4.1$ & $6.9 \pm 4.4$ & $13.0 \pm 5.8^{*}$ & $4.9 \pm 3.5$ & $13.0 \pm 7.3^{* *}$ \\
\hline & & $4.2 \pm 2.4$ & $14.5 \pm 10.5^{* *}$ & $5.1 \pm 2.1$ & $10.8 \pm 6.0^{* *}$ & $4.8 \pm 4.3$ & $10.4 \pm 7.8^{*}$ \\
\hline
\end{tabular}

\footnotetext{
$* \mathrm{p}<0.05 * * \mathrm{p}<0.01$ (Young vs Aged), \#<0.05 \#\#<0.01 (Male vs Female).
} 
point were lower at the U-D axis in the aged group, although the average accelerations showed a slight difference between the two groups at the B-F and R-L axes.

The differences between sexes in terms of the average accelerations at the lumbar and knee points were small at all axes during the movements. The average accelerations at the ankle point in the young group were higher in males than in females at all axes during the movements. Those at the toe point in the young group were higher in males than in females at the $\mathrm{B}-\mathrm{F}$ and $\mathrm{U}-\mathrm{D}$ axes during the movements.

\section{Discussion}

The new instrument has enabled us to measure leg motions using a three-dimensional accelerometer during the performance of physical fitness activities and walking. The average accelerations of the leg motions showed differences between the young and aged groups.

The new instrument developed in this study can be used to measure leg motions. There are some earlier reports on estimating movement coordination with three axes at one lumbar point (20). The key feature of this new instrument is that it can simultaneously measure leg motions at four points.

The measuring directions of the acceleration sensors depend on the body position during the movements, because the original directions are set at mutually vertical positions. The new equipment cannot correct the values measured during movements to the values at the axis before the movements. Thus, we used the measured values as the values measured at the axis parallel to the sagittal, horizontal or vertical axis at the standing position before the movements.

A portable device measuring three-dimensional acceleration was previously introduced for evaluating walking movements (20). The system introduced in this study can measure three-dimensional accelerations while the subjects are performing physical fitness activities or walking. The different walking styles produce different accelerograms because of the undulate patterns of the signals that are related to the leg motions. The average accelerations at the R-L axis were higher by two points from the subject with a flatfoot. The average acceleration at the R-L axis during walking shows a walking style characterized by staggering. Consequently, the subject with a flatfoot walked with more pronounced staggering than those without a flatfoot. The difference in movements may result from the different movement coordinations during walking. The toe motion during walking also reflects movement coordination and walking speed (21). The accelerogram, therefore, may reflect movement coordination as one of the factors affecting leg motion.

The average accelerations at the lumbar point show the stability of the trunk during movements. The weak muscle power of the legs and the poor movement coordination disturb the stability of the trunk and increase the average acceleration. The average accelerations at the knee point show the stability of the knee joint. In the elderly persons, the decreased elasticity of the medial and lateral menisci leads to a decreased number of up and down movements and an enhanced dislocation from front to back and from side to side. Thus, the average acceleration at the U-D axis decreases and those at the B-F and R-F axes increase. The average accelerations at the ankle point show the stability of the ankle, and those at the toe point show the stability of the toe. The decreased movement coordination leads to the increased average acceleration at both points.

The aged subjects showed a lower average acceleration at the U-D axis at the knee point but a higher average acceleration at the toe, ankle and lumbar points. These results suggest that the body at the knee point slowly moves up and down in the aged subjects although it vibrates from front to back and from side to side rapidly and that the movements at the toe, ankle and lumbar points are rapid. These may result from the poor movement coordination of the knee joint (22) and the weak power of the muscles, such as the quadriceps in the aged group (16-19).

The sex differences in the average accelerations were small. In the young group, the average accelerations at the ankle and toe positions were higher in males than in females. This is because there were six young male subjects who were athletes. A very strong muscle power makes the ankle and toe positions less stable, because this strong power cannot maintain the ankle and toe positions in a suitable position.

The measuring time used by the new system is short. No one complained about the measurement activities even among the aged subjects. The measuring system introduced here seems not to be a burden to the subjects and enables us to measure the average acceleration even among the elderly persons.

The muscle power of the legs and movement coordination have been measured by leg myodynamiometry and electromyography in the static state (12-19). The validity of the measured data results in various interpretations, because a fall often occurs in the dynamic state (1-4). Recently walking movements have been paid attention to because walking speed is significantly related to fall prevention (5-11).

Functional reach is widely used in various clinical methods due to its simplicity and it has a close relationship with the incidence of a fall, activities of daily living, social activities, walking speed and one-foot-leave retention time. This method shows the overall movement coordination in the dynamic state $(23,24)$. However, functional reach does not reflect leg motions in real time, since a fall occurs because of the instantaneous lack of movement coordination $(23,24)$. The test itself occasionally induces a fall among the subjects.

A gravicorder is clinically used to evaluate and confirm the effects of therapy on disorders of movement coordination at the static state (16-19). Because this method aids in the diagnosis of central nerve dysfunction or equilibrium dysfunction of the visual or auditory sense, it has recently been used in trial studies for fall prevention. However it is impossible to observe central nerve functions or movement coordination under dynamic conditions. Also the importance of the gravicorder for preventing a fall has not been reported yet among the healthy elderly (25-27).

The Get-up-and-Go Test is an index of total mobilization ability (28). Although the result is judged using the evaluation index of five stages, it is not quantitative compared with the accelerogram (28). The force plate is effective for measuring mechanical coordination at the dynamic state. However, the measurement of the motion region of a subject is limited and it 
is impossible to present leg motions using a visible method (29-31).

The half squat movement is used for the typical training of the body for movement coordination. This movement is suitable for checking proper movement coordination. However it creates a heavy burden and is difficult to apply to all aged subjects because of the large difference in physical strength. This movement occasionally induces fractures of the femur of aged subjects. Consequently, this type of movement was not applied to the subjects in this study.

In this study, the accelerogram of the leg motions can show information on leg motions at the dynamic state, and may be used as a new index for evaluating leg motions at the dynamic state. Information from the accelerogram may be used to prevent a fall of elderly persons, although further studies are necessary to clarify this point.

\section{Conclusions}

The new instrument has enabled us to measure leg motions using a three-dimensional accelerometer during the performance of physical fitness activities and walking without giving burden to the subjects. An accelerogram may reflect the muscle power of the legs and movement coordination. Consequently, an accelerogram may be used as a new index for evaluating leg motions at the dynamic state.

\section{Acknowledgements}

The authors are grateful to Ms. Yuki Sakamoto, Ms. Mari Shimohigashi, Ms. Kimiko Yuba, elderly persons in Nokami Town and Hanazono Village in Wakayama Prefecture in Japan, and young students at Wakayama Medical University, School of Health and Nursing Science and Wakayama University, Faculty of Education for their support in the conduct of this study.

This study was supported by the Medicine Promotion Association in Wakayama Prefecture.

Scand Suppl. 1986;711:227-232.

(11) Nagasaki H, Itoh H, Furuna T. A physical fitness model of older adults. Aging (Milano). 1995;7:392-397.

(12) Province MA, Hadley EC, Hornbrook MC, Lipsitz LA, Miller JP, Mulrow CD, et al. The effects of exercise on falls in elderly patients. A preplanned meta-analysis of the FICSIT Trials. Frailty and Injuries: Cooperative Studies of Intervention Techniques. JAMA. 1995;273:1341-1347.

(13) Obuchi S, Shibata H, Yasumura S, Suzuki T. Relationship between walking ability and risk of falls in community dwelling elderly in Japan. J Phys Ther Sci. 1994;6:39-44. (Article in Japanese)

(14) Lord SR, McLean D, Stahers G. Physiological factors associated with injurious falls in older people living in the community. Gerontol. 1992;38:338-346.

(15) Masakado Y, Noda Y. Relation between macro-EMG and muscle fiber conduction velocity. Electromyogr Clin Neurophysiol. 1995;35:295-300.

(16) Murray MP, Seireg A, Scholz RC. Center of gravity, center of pressure, and supportive forces during human activities. J Appl Physiol. 1967;23:831-838.

(17) Ring C, Nayak US, Isaacs B. Balance function in elderly people who have and who have not fallen. Arch Phys Med Rehabil. 1988;69:261-264.

(18) Fernie GR, Gryfe CI, Holliday PJ, Llewellyn A. The relationship of postural sway in standing to the incidence of falls in geriatric subjects. Age Ageing. 1982;11:11-16.

(19) Kirby RL, Price NA, MacLeod DA. The influence of foot position on standing balance. J Biomech. 1987;20:423-427.

(20) Tanikawa T, Ohta S, Nagao M, Miyakawa T. A measurement of a walk movement using a portable three dimensional accelerometer. Kawasaki Med Welfare. 2002;12:103-107. (Article in Japanese)

(21) Kobayashi Y, Takataya K, Yamagishi H, Takizawa T. Influence on the gait of wearing equipment for the experience of the aged. Yamanashi Nursing. 2002;1:33-36. (Article in 
Japanese)

(22) Kinugasa T, Haga S, Esaki K, Furuna T, Suguura M, Katsumura T, et al. Exercise intervention study on the physical fitness, functional capacity and health status of low-fit elderly people living in the community. Jpn Soc Exerc Sports Phy. 2005;12:63-73. (Article in Japanese)

(23) Duncan PW, Weiner DK, Chandler J, Studenski S. Functional reach: A new clinical measurement of balance. J Gerotol. 1990;45:M192-M197.

(24) Duncan PW, Studenski S, Chandler J, Prescott B. Functional reach: Predictive validity in a sample of elderly male veterans. J Gerontol. 1992;47:M93-M98.

(25) Maki BE, Holliday PJ, Fernie GR. Aging and postural control: A comparison of spontaneous and induced-sway balance tests. J Am Geriatr Soc. 1990;38:1-9.

(26) Brauer SG, Burns YR, Galley P. A prospective study of laboratory and clinical measures of postural stability to predict community-dwelling fallers. J Gerontol A Biol Sci Med Sci. 2000;55:M469-476.
(27) Bogle Thorbahn LD, Newton RA. Use of the berg balance test to predict falls in elderly persons. Phys Ther. 1996;76: 576-583.

(28) Mathias S, Nayak US, Isaacs B. Balance in elderly patients: the "Get-up and Go" test. Arch Phys Med Rehabil. 1989; 67:387-389.

(29) Tamura T, Yoshimura T, Horiuchi F, Higashi Y, Fujimoto T. An ambulatory fall monitor for the elderly. World Congress on Medical Physics and Biomedical Engineering. 2000; July 23-28, Chicago, USA.

(30) Sekine M, Tamura T, Fujimoto T, Fukui Y. Classification of walking pattern using acceleration of walking waveform in elderly people. World Congress on Medical Physics and Biomedical Engineering. 2000; July 23-28, Chicago, USA.

(31) Sekine M, Abe Y, Sekimoto M, Higashi Y, Fujimoto T, Tamura T, et al. Assessment of gait parameter in hemiplegic patients by accelerometry. World Congress on Medical Physics and Biomedical Engineering. 2000; July 23-28, Chicago, USA. 